\title{
La investigación narrativa como moción epistémico-política*
}

\author{
María Marta Yedaide,' Zelmira Álvarez² y Luis Porta ${ }^{3}$ \\ Grupo de Investigaciones en Educación y Estudios Culturales (Gieec) \\ Universidad Nacional de Mar del Plata (Argentina)
}

Recibido: enero 28 de 2015 - Revisado: febrero 11 de 2015 - Aceptado: mayo 20 de 2015

Referencia formato APA: Yedaide, M. M., Alvarez, Z., \& Porta, L. (2015). La investigación narrativa como moción epistémico-política. Revista

Cientifica Guillermo de Ockham, 13(1), 27-35.

\section{Resumen}

La investigación narrativa se encuentra necesariamente atravesada por la disputa acerca del sentido de lo que es investigar y lo que puede y debe esperarse de esta empresa. Si bien su legitimidad epistémica y su uso asiduo en el estudio de la educación han ido creciendo proporcionalmente, su validez metodológica sigue despertando inquietudes que remiten no solo a cuestionamientos técnicos, sino que también arrastran posturas políticas respecto de la naturaleza de la realidad, el lugar de los sujetos en el devenir de la experiencia humana y el poder de la práctica científica en el juego de las construcciones de sentido. Este trabajo se aboca al análisis del estado de la cuestión en el contexto geográfico inmediato y su marco geopolítico más general y sostiene las preguntas respecto de las consecuencias políticas de la investigación narrativa. Comparte, asimismo, retazos narrativos de profesores entrevistados en la Universidad Nacional de Mar del Plata (UNMdP) al intentar dar cuenta de la buena enseńanza, como modo de ilustrar la potencia política de este tipo de indagaciones.

Palabras clave: Educación superior, investigación narrativa, validez metodológica, moción epistémico-política

\section{Narrative inquiry as an epistemic and political drive}

\section{Abstract}

Narrative inquiry is inevitably involved in the disputes regarding the very meaning of what investigating is, and what can and must be expected from this enterprise. Even if the epistemological legitimacy and their devoted use of

* Este artículo se deriva del proyecto Formación del profesorado VI: (auto)biografias y narrativas de instituciones, estudiantes y profesores memorables. Conocimiento, pasiones, emociones y afectos desde una mirada decolonial, 2014-2015, del Grupo de Investigaciones en Educación y Estudios Culturales (GIEEC), Centro de Investigaciones Multidisciplinarias en Educación (CIMEd), Facultad de Humanidades, Universidad Nacional de Mar del Plata.

1. Profesora e investigadora del Departamento de Ciencias de la Educación de la Facultad de Humanidades, Universidad Nacional de Mar del Plata (UNMdP). Miembro del Centro de Investigaciones Multidisciplinarias en Educación (CIMEd) y del Grupo de Investigaciones en Educación y Estudios Culturales (GIEEC) de Facultad de Humanidades, UNMDP. Doctoranda en Humanidades y Artes con mención en Ciencias de la Educación, Universidad Nacional de Rosario (UNR). Profesora de inglés y especialista en docencia universitaria. Directora Asociada Revista EntramadosEducación y Sociedad. Dirección postal: Martínez Zubiría 1735, (7600), Mar del Plata, Argentina. E-mail: myedaide@gmail.com

2. Profesora Universitaria de inglés y especialista en docencia universitaria por la UNMDP. Es titular de Gramática Inglesa y Teorías del Sujeto y del Aprendizaje en el Departamento de Lenguas Modernas, FH, UNMDP. Es investigadora integrante del grupo en Análisis del Discurso (FH), dirigido por el S. M. Menéndez, y codirectora del proyecto actual del grupo GIEEC (FH) bajo la dirección del Luis Porta. E-mail: zelmiraralvarez@gmail.com

3. Profesor Titular regular con dedicación exclusiva e Investigador (categoría I) del Departamento de Ciencias de la Educación de la Facultad de Humanidades, Universidad Nacional de Mar del Plata (UNMdP). Investigador categoría Independiente de la carrera de investigador científico del Consejo Nacional de Investigaciones Científicas y Técnicas (Conicet). Doctor en Filosofía y Ciencias de la Educación, con orientación en pedagogía por la Facultad de Ciencias de la Educación, Universidad de Granada, España (1999). Es Vicedirector del Centro de Investigaciones Multidisciplinarias en Educación (CIMEd) y Director del Grupo de Investigaciones en Educación y Estudios Culturales (GIEEC) de Facultad de Humanidades, UNMDP. Director de la carrera de posgrado de Especialización en Docencia Universitaria (UNMdP). E-mail: luis_porta@hotmail.com 
educational research have been rising proportionally, its methodological validity still generates controversy, not only in regard to technical issues but rather, and more importantly, related to political stances as to the nature of reality, the place of subjects in ongoing human experience and the power of scientific practice in the game of building sense. This paper addresses the analysis of the state of the matter in the immediate geographical context and the larger geopolitical extent, and poses the questions regarding the political consequences of narrative inquiry. In addition, some narrative fragments by university professors from the State University in Mar del Plata, Argentina, are shared, in order to illustrate the political potential of these types of inquiries.

Keywords: Higher education, narrative inquiry, methodological validity, epistemological, political drive

\section{Investigação narrativa como movimento epistêmico-político}

\section{Resumo}

A investigação narrativa é necessariamente atravessada pela disputa sobre o significado do que é investigar, e o que pode e deve se esperar desta empresa. Embora sua legitimidade epistêmica e seu uso regular no estudo da educação passaram aumento proporcional, sua validade metodológica ainda continua levantando preocupaçóes que se referem não só às questôes técnicas, mas arrastando pontos de vista políticos sobre a natureza da realidade, o lugar dos sujeitos no curso da experiência humana e o poder da prática científica no jogo das construçóes de sentido. Este trabalho volta-se para a análise do estado das coisas no contexto geográfico imediato e seu quadro geopolítico mais amplo, e apoia as questóes relativas as consequências políticas da investigação narrativa. (Narrativa) também compartilha trechos narrativos de professores entrevistados na Universidade Nacional de Mar Del Plata (UNMdP) ao tentar explicar o bom ensino como forma de ilustrar o poder político dos inquéritos.

Palavras chave: Ensino superior; pesquisa narrativa; solidez metodológica; movimento epistêmico-político

\section{Introducción}

Podemos decir que hemos superado en gran medida la necesidad de justificar "lo cualitativo" en las ciencias sociales y humanas, lo cual puede y debe ser visto como una conquista semiótica sustantiva en términos de los usos y fines de la investigación. Aquellos postulados del siglo XIX que recuperaban la singularidad que el estudio del hombre y sus circunstancias exigían, y el incipiente reconocimiento de la historia y de la complejidad de lo social, fueron sucedidos por un tiempo de revisión intensa, de cuestionamiento y juicio de las implicancias de su contraparte racional-tecnocrática. El giro lingüístico y el giro hermenéutico pueden advertirse hoy como hitos del siglo XX que señalan el abandono de ciertas pretensiones para el estudio de lo humano, por un lado, y la habilitación sociocultural para otras prácticas del conocer, ${ }^{4}$ por el otro. Las exigencias de especificaciones relativas a la inscripción de los proyectos de investigación en lógicas cuantitativas, cualitativas o mixtas quedaron obsoletas -incluso ridículas- al abandonar las distinciones como meras opciones metodológicas y reconocer en cambio sus implicancias y alcances paradigmáticos.

Las sospechas incipientes sobre la validez metodológica de los enfoques e instrumentos cualitativos, se volcaron así sobre su par dicotómico tan pronto como se advirtiera la insoslayable inscripción de la ciencia en la historia y la intervención de la cultura - "afectada" por sus condicionantes materiales- en la construcción de las teorías. Las inquietudes filosóficas de la modernidad se traducían ahora en cuestionamientos provenientes desde el propio corazón de la ciencia, desdibujando así fronteras entre lo físico y lo humano, primero, y desafiando a la postre distinciones rotundas entre la teoría y la lírica, lo denotativo y la metáfora. Hemos alcanzado (intentaremos

4. Se ha propuesto en otros trabajos esta categoría en tensión con la formulación de Violeta Guyot (2007, p. 8) sobre las prácticas del conocimiento. Mientras que estas últimas preservan distinciones clásicas entre diversos tipos de conocimientos, la frase "prácticas del conocer", o "prácticas del conoser" como se ha aventurado, recupera la dimensión práctica de toda empresa humana, incluida la de inteligir aquello que la experiencia trae al ámbito de la conciencia. Decir que el conocimiento es un sedimento de una práctica intelectual es diferente fundamentalmente en un sentido epistemológico-político, con necesario arrastre de supuestos ontológicos, y altera el modo de abordar y comprender el agenciamiento de los sujetos en la construcción y transformación de su entorno (Porta \& Yadaide, 2014). 
argumentar) un estado de inquietud profunda respecto de nuestra posibilidad de conocer independientemente y una concomitante resolución política de actuar según estas nuevas coordenadas.

Si bien este giro radical no está aún instalado -la ciencia, con sus teorías "incontaminadas" y objetivas, goza de excelente salud tanto por su legitimidad simbólica como por su reconocimiento material-sostendremos con Ryan (1999) que hay un movimiento, una "marea" que se ha gestado y se aproxima, cuyo alcance se hace inminente. Este fenómeno, que se conjuga con el reconocimiento de los límites humanos para conocer (Morín, 1999), se presenta, no obstante, como una posibilidad histórica de redefinir las reglas de juego de la producción científica rotundamente.

Este trabajo se ubica en las zonas de momento híbridas y aún en disputa respecto de los enfoques y las metodologías narrativas en la investigación social. Propone asomarse al paisaje de la suspensión de pretensiones científicas absolutas -a las cuales condena por su voluntad hegemónica-y mostrar la potencia de la narrativa específicamente por su singularidad, su localidad y su inmediatez. Comienza por la disputa paradigmática, transita los sentidos políticos que la narrativa adopta en la actualidad y elabora una suerte de paneo, una vidriera para la exposición de algunos fragmentos narrativos que legitiman su validez en la potencia de la construcción y transformación de los escenarios de la educación.

Este trabajo en particular, desplegará síntesis provisorias de las tesis conceptuales avanzadas en los dos primeros apartados, mientras que proporcionará el acceso del lector al campo mediado por el relato en la última sección, de modo de revelar tanto los fundamentos como las claves en el hacer y el tipo de conocimientos que ambos habilitan.

\section{La investigación narrativa. Razones epistemológicas}

La investigación como producción de verdad ha encontrado inexorablemente sus límites ontológicos y suscitado así tanto la muerte de su sueño positivista como la restauración del signo vital de la acción política. Los cuestionamientos ontológicos contemporáneos respecto de la naturaleza de lo real -de ningún modo novedosos pero de extrema vigencia hasta hace unos años en el pensamiento occidental- se han impuesto en la agenda de la ciencia sin remedio. No es estrictamente una negación de la entidad de lo real, sino más bien una aceptación de la necesaria mediación de lo humano en la captación de tales hechos o fenómenos (Ryan, 1999). No existiría, se acuerda, forma de acceso a lo que es que no se encuentre mediada o traducida -cooptada, si se quiere- por las construcciones simbólicas de las comunidades cognoscentes. La experiencia humana no es posible de ser escindida de los objetos de su interés, de constitución híbrida-material y simbólica inseparablemente. La verdad a partir de esta verdad (la repetición pone intencionales signos de pregunta a la afirmación, que no serán desarrollados en este trabajo, pero deben ser expuestos) queda reducida a verdades (en plural) que no serían, no obstante, caprichosas o casuales. El relativismo cultural asiste, también, a su entierro; las construcciones sociales que median en la interacción con la experiencia no son producto del libre albedrío de los humanos, sino formas complejas y contingentes resultado de la historia y las condiciones materiales y simbólicas allí inscriptas y sus formas de devenir.

Estas certezas -reiteramos las sospechas que nos genera desafiar las viejas verdades para encontrarnos con otras nuevas, inquietantemente generalizables- respecto de los límites de acceso a la realidad, se han traducido no solo en cuestionamientos ontológicos relativos a los objetos del conocimiento y sus modos de abordaje, sino fundamentalmente éticos respecto de las motivaciones y las consecuencias de las empresas científicas. En el caso de las llamadas ciencias duras, sobrevive la mirada pragmática y es posible continuar como si la objetividad y la universalidad pudieran sostenerse. En el caso de las ciencias humanas y sociales, el costo de preservar una racionalidad tecnocrática radical-que es no obstante frecuente en, por ejemplo, las condiciones de anonimato para las publicaciones científicas y las lógicas de financiación y autorización de proyectos de investigación-, es demasiado alto. Es muy difícil hoy justificar la producción de conocimiento académico sobre los sujetos como si estos fueran objetos y el investigador un mero instrumento neutro de aproximación a su estudio. Es, asimismo, difícil ignorar los efectos concretos de ciertas teorías en el acervo simbólico de la humanidad, sus consecuencias éticas y políticas.

Como sostiene Vasilachis de Gialdino (2012), nos encontramos en el tránsito entre "la forma de conocer, legitimada, admitida, a las diversas formas de conocer" (p. 11). Esto implica, por un lado, el necesario abandono de las pretensiones universalistas y objetivistas que enunciáramos -además de la potencialidad explicativa y predictiva de los fenómenos- y la restitución del agenciamiento político por el otro. También desplaza los imperativos metodológicos hacia el interés por el sentido último de la empresa investigativa, lo que supone una transición 
-como decíamos arriba- desde preocupaciones técnicas a cuestiones éticas.

El desafío a la verdad única y el abandono de la voluntad de ampliación del conocimiento es sustituido por la confianza en la potencia performativa (Kincheloe \& McLaren, 2012) de las nuevas teorías en cuanto movimientos hacia la transformación social. Lo que se cuestiona, finalmente, es el régimen de verdad como autoridad de representación. ¿Quién puede decir qué es verdad? La respuesta a este interrogante también señala la distribución del poder de construcción de la realidad que ostentan diferentes facciones de las comunidades de modo altamente inequitativo. Esto nos deja en el umbral de las consideraciones políticas que describiremos en el próximo apartado.

De vuelta al hilo argumentativo respecto de la actual crisis epistemológica, ${ }^{5}$ las preocupaciones por las formas de abordar metodológicamente los problemas dignos de ser investigados se redoblan al considerar los procesos de interpretación de la información producto del ingreso de los investigadores al campo. En otras palabras, la opción paradigmática de base-que no puede alejarse claramente de las configuraciones cosmogónicas y queda entonces sujeta a los avatares imprecisos y acientíficos de las creencias- privilegia la semántica por sobre las construcciones sintácticas de las técnicas. La gramática de las nuevas formas de investigar se procuran medios eficaces para generar validez dialógica, autorreflexiva o contextual (Denzin \& Lincoln, 2012), aun cuando esto implique la creación o invención de nuevas herramientas y luego enfatizan la fidelidad de los hallazgos sobre la base de estos mismos criterios de validez, que implican nuevos estándares para la justificación de las conclusiones.

El escape a otras formas de validación de los hallazgos, que constituye tal vez el desafío más resonante a las lógicas positivistas y pospositivistas, es claramente intencional. Sin el amparo de una única verdad por ser descubierta, se opta abiertamente por una validez catalítica (Kincheloe \& McLaren, 2012) que cobra sentido porque se advierte que los sujetos de las sociedades contemporáneas están sujetados a estructuras alienantes. Al decir de Kincheloe y McLaren, "las estructuras sociales no determinan sino que constrińen a los actores de manera muy intricada" (Vasilachis de Gialdino, 2012, p. 20), y estos lazos de sujeción son pasibles de ser desarmados mediante la explicitación o el uso de la palabra para decir aquello que de otra forma nunca será dicho. Por el contrario, el riesgo de construir leyes de lo social radica en que estas sean percibidas como determinantes e inhiban la acción social al destituir las posibilidades alternativas de nombrar.

En términos de efectos, este abandono de la ilusión de certeza de la ciencia moderna conlleva esfuerzos concretos para asumir la ambivalencia -mejor dicho, la multivalencia- de los fenómenos que intentamos comprender y la consiguiente ambigüedad que resulta de la fuga del universalismo y las abstracciones. Su contraparte se manifiesta como una entrada a lo contextual, a los puntos de vista situados y el carácter ahora imprescindible de la validez dialógica (Saukko, 2012).

También implica el concierto de voces -o polifoníaque resulta del empoderamiento de aquellos que sin hacer ciencia pueden no obstante colaborar en la construcción de un conocimiento que los implica. De esta manera, se materializa una praxis política y se da luz a nuevas conciencias híbridas o mestizas, mezcladas y confundidas, pero nítidas en su voluntad transformadora.

La narrativa no es privativa de ninguna tradición científica, ni de su fundamentación paradigmática. Es una competencia de la raza humana, un medio vital para la supervivencia de la especie. Ha servido tanto a la ciencia europea positivista como sirve a las alternativas arriba enunciadas. Sin embargo, su participación necesaria en toda empresa humana y el consiguiente problema que presenta para el respaldo de la objetividad han cobrado preeminencia en los últimos tiempos. Las complejas tramas entre el lenguaje y la cultura, entendida esta como una malla o red de significados (Geertz, 1987) y su participación en la construcción de los conocimientos, han contribuido al descrédito de las verdades únicas y la posibilidad concreta de acceder a lo que existe sin mediación. En otras palabras, mucho de lo acontecido como revuelta ontológica con derrame en la epistemología se asocia, precisamente, a los límites de la narrativa, que ha conducido a "la preeminencia paradigmática de la ontología y de la epistemología incorporada de modo efectivo una en la otra" (Guba \& Lincoln, 2012, p.51).

Bruner (1997) aporta, desde la perspectiva psicológicaconstructivista social, una mirada de la narrativa en la que la creación del conocimiento no se despega de la construcción de la subjetividad. Aborda la narratividad como una facultad humana para integrar lo nuevo a lo

5. Se habrá observado que el uso del término epistemología no conserva en el artículo el sentido estrecho de estudio de la ciencia moderna, sino que se extiende para nombrar y problematizar las condiciones de posibilidad de construcción de conocimientos de índole no científica-incluso acientífica-, tal como lo proponen, entre otros, los pensadores descoloniales (Santos, 2009). 
canónico en las redes semánticas que dan inteligibilidad a la experiencia y se vuelven así públicas en el sentido de posible de ser compartidas. Las narrativas no solo construyen la red que Geertz propone, sino que conforman encastres institucionales para el anclaje del yo, o self(Bruner, 2003). Si bien esto deja fuera las prácticas sociales no lingüísticas, igualmente potentes en la construcción de sentidos (Angenot, 2012), el lugar de la narrativa como posibilidad y límite claramente desafía las pretensiones de una ciencia en búsqueda de una verdad y de un sujeto que puede escindirse de los objetos que estudia.

\section{La investigación narrativa. Razones políticas}

Al hablar de un régimen de verdad, lo que queda al descubierto es el vínculo íntimo entre verdad y relaciones de poder en cuanto potencial para moldear la experiencia humana. En otras palabras, la construcción de conocimiento socialmente legitimado alberga el poder de definición matricial del mundo simbólico que habitan las personas. Allí radica su inmenso potencial hegemónico. Como dice Vasilachis de Gialdino (2012), "las afirmaciones acerca de la verdad están discursivamente situadas en las relaciones de poder" (p. 16). Los hechos ya no pueden ser escindidos de su inscripción ideológica o su construcción histórica con impunidad; los lazos entre lo legitimado y los agentes y condiciones oferentes de tal legitimación han quedado inevitablemente expuestos.

Del mismo modo que la Nueva agenda de la didáctica (Litwin, 2005) supone pensar la buena enseñanza irremediablemente desde una perspectiva moral, la investigación en educación ya no puede ser valorada únicamente en función de sus procedimientos, sino en virtud de los fines a los que se orienta y los modos como su hacer construye o aniquila las posibilidades políticas de las personas implicadas. En este sentido, tanto el objetivo o razón de ser que impulsa la investigación, como el papel que desempeñan todos los participantes de la investigación (con necesaria fluidez en la distribución del poder y el habla entre el "científico" y los otros sujetos involucrados) y los hallazgos comprendidos como ampliación colectiva y creativa de la conciencia; todo esto responde a un acto moral. De hecho, a medida que los modos de garantizar validez metodológica se hacen difusos e insostenibles, "la objeción a la neutralidad valorativa y al carácter objetivo del conocimiento lleva a afianzar la actualidad del compromiso ético" (Vasilachis de Gialdino, 2012, p.12).
Este estado de la cuestión respecto de las ciencias sociales y humanas en general, y de la educación en particular, no ha llegado a constituirse de forma casual, sino más bien como una conquista semiótica sostenida en gran medida desde la teoría crítica y el pensamiento decolonial y sus múltiples afluentes. No ha habido "descubrimientos" de la ciencia como producción socialmente legitimada -y por tanto, expresión del poder hegemónico-sino más bien un interés sostenido por la emancipación de las conciencias que ha expuesto las variadas formas en que lo simbólico y lo material se entrecruzan y retroalimentan en la historia de los pueblos. La ciencia queda así cartografiada en el mapa más abarcador de las formas de colonización originalmente militar $\mathrm{y}$ territorial $-\mathrm{y}$ seguidamente $\mathrm{y}$ hasta nuestros días, simbólicas- iniciadas en el siglo XV. El encuentro entre la civilización occidental y el resto de los pueblos de la Tierra, impuso la construcción de nuevas identidades espejadas en las que las escisiones dicotómicas del pensamiento europeo y su ilusión de historia común y universal resituaron la historia de todos los otros pueblos del mundo a su imagen y medida (Lander, 2011). La ciencia moderna generó, como el resto de las instituciones occidentales, imperativos de legitimidad absoluta para una forma local, particular y provinciana, de inteligir la experiencia. Logró así justificar algunas heterarquías jerárquicas por sobre las demás y asegurar la dominación sobre la base de la traducción de la diferencia en brutalidad, primitivismo e inhumanidad (Cairo \& Grosfoguel, 2010).

Pero los pueblos sublevados, aún a espaldas de la historia que no quiso decirlos, comenzaron, no obstante, a escribir otras narrativas que solo recientemente se han elevado a las alturas del conocimiento científico e ingresar a la historia. La revolución haitiana es, probablemente, el ejemplo más potente de lo inconcebible, de la negación absoluta de la humanidad del otro asumido como naturaleza, digno así de sumisión y control (Grüner, 2010).

En esta configuración moderna de lo humano y sus luces y sombras, el conocimiento científico ejerció un papel protagónico. Escondido tras la hybris del punto cero (Castro-Gómez, 2005) -al silenciar su corpo y geopolítica (Mignolo, 1999) y presentarse como forma única, libre, de conocer- la ciencia se constituyó en los términos y las condiciones de la opresión.

\section{La investigación narrativa. Potencia para la comprensión de lo educativo}

A continuación, nos permitiremos compartir algunos retazos narrativos emergentes de entrevistas en profundidad con profesores de la Universidad Nacional de Mar 
del Plata, Argentina, señalados por sus estudiantes como ejemplos de buena enseñanza. Nuestro interés en la búsqueda de claves para la formación de formadores, nos ha conducido, paulatinamente a los intentos por comprender las razones que fundamentan la buena enseñanza en el contexto universitario y nos ha dejado a las puertas de los universos simbólicos que los docentes distinguidos habitan.

La elección por el método narrativo - profundizado en el enfoque (auto)biográfico narrativo en una etapa de la investigación y ampliado luego hacia otras herramientas y metodologías de indagación como las historias de vida, las observaciones participantes y no participantes, y los grupos de discusión- ha sido potente en la posibilidad de acceso a conocimientos, que lejos de manifestarse con la rigurosidad y monosemia de las teorías científicas, se presentan con las ambigüedades, plurivalencias y consistencia híbrida de las teorías explicativas más intuitivas o personales, de especial valor en cuanto atesoran los fundamentos o sentidos finales y trascendentes de la enseñanza.

Comenzaremos por algunos retazos que ilustran este tipo de conocimientos mestizos, especialmente manifiestos en relación con los métodos y los sentidos de la enseñanza y sus fundamentos: ${ }^{6}$

[Al relatar los fracasos escolares iniciales]. Entonces, les pregunté a las chicas, que eran muy competitivas y conocían el sistema, pero no querían decir cómo hacían. Y había un tipo que me cayó muy bien. Que me decía que no fuera tonto; que había que leer un poquito todo y después aprender a improvisar. No aprender la lección, aprender a improvisar. Con lo cual fue mi profesor pedagógico; de lo que es concepto y no memoria. Fue una ayuda mágica. (A1).

El sentido de la enseñanza es darles herramienta para que después ellos puedan multiplicar, puedan ir más allá; es decir, abrirles el apetito del saber y del placer de la literatura. (L1)

Miles de años después, en Barcelona, en un curso de posgrado-doctorado, aparece Kepler y dice "Lo mejor que puede hacer un profesor es no enseñar nada, porque cuando enseña está achicando el mundo". Es genial, es abrir un camino y dejarlo caminar. Pero no enseñar, no marcar, porque eso te achica el mundo. (A1)

Siempre hay algo escénico en la clase; es porque vos estás manejando el interés de un conjunto de personas que tienen veintisiete cosas en qué pensar y demás, pero que uno tiene que ser tan potente en el atractivo de lo que está enseńando; hacer más atractivo, porque hay cosas que son más duras que un hueso, yo creo... ahí está el trabajo, hay un trabajo casi teatral de poner en escena los conocimientos (L1)

De ahí que te digo cuál es mi método pedagógico: conocer mucho el tema y tener muchas ganas (E1)

En todos estos retazos narrativos, las definiciones sobre qué es enseñar y para qué se enseña aparecen alejadas de formulaciones teóricas de la didáctica. Por el contrario, se enraízan en las experiencias personales, las convicciones, los aprendizajes vitales. El uso del lenguaje metafórico, en estas y otras narrativas afines, expone la irreverencia a la rigurosidad disciplinar al momento de referirse a estas cuestiones.

Otro hallazgo de especial importancia ha sido el reconocimiento del otro en la enseñanza, mediado necesariamente por el compromiso en el afecto y por él, y el valor de lo vincular. Si bien el alumno es objeto de análisis en la didáctica y su implicación una fórmula para el éxito académico, las dimensiones aquí expuestas trascienden el sujeto racional construido y permiten el involucramiento personal, más íntimo, de un sujeto sensible a otro sujeto sensible:

[hablando de los estudiantes] Yo tengo por ellos... mucho respeto. Sí. Me encanta tratarlos. (...)

Me enamoro de la manera de ser de ellos (...) los chicos y las chicas me atraen muchísimo (E1)

[sobre los alumnos] Son ellos los que me invitan a que convide, a que diga, a que cuente. Son ellos. Te tientan muchisimo. Tienen una atracción tremenda. (A1)

El afecto se construye a partir de esa primera percepción del alumno como un par, como un par antropológico, lo cual no disuelve las jerarquías iniciales en el sostenimiento de la práctica. Indudablemente, yo sé más filosofía que aquellos que tengo enfrente, lo cual no implica que el primer posicionamiento no sea el reconocimiento de esos alumnos como pares; como pares en su condición de sujetos, sin prejuicios, sin algunas imágenes frecuentes en los tiempos que corren, de presuponer la juventud desde tales y cuales cuestiones: la improductividad, el escaso bagaje que traen en algunos casos, la criminalización de los jóvenes, una serie de preconceptos que me consta nos atraviesan como profesores, de los cuales resulta difícil sustraerse, porque esas miradas generalmente de sesgo negativizado en torno a los jóvenes, son las que nos hablan como profesores. El tiempo histórico los criminaliza, por lo tanto, construir el entramado afectivo, es poner en marcha la voluntad. (F1)

6. Las cursivas en cada cita son nuestras e intentan recuperar para el lector las instancias críticas que ilustran los nudos de conocimiento descritos.

$32<$ Universidad de San Buenaventura, Cali - Colombia 
Una buena persona, un buen profesor apasionado y que es buena persona, para mí es alguien que está abierto a los alumnos, que los considera por más que sepan menos que él, personas equivalentes; no hay nada que me parezca más abominable que un profesor que trata mal a un alumno, que lo desprecia; es decir, el respeto a la persona (L1).

Para mí, la docencia no pasa solamente por transmitir conocimientos teóricos; hay una fuerte impronta de ellos pero fundamentalmente yo creo que nace a partir de la vinculación interpersonal entre el docente y el alumno (G2)

Desde el amor hasta el respecto, e incluso el simple reconocimiento de la necesidad recíproca del otro, se tejen en las narrativas docentes las posturas existenciales respecto de la enseñanza y su relación con el aprendizaje.

Este desdibujamiento de lo académico o disciplinar, por un lado, y lo personal, por el otro, también se hace evidente en un enlace inesperado pero obstinadamente recurrente en las entrevistas que expone la profunda intimidad entre lo profesional y la vida:

Yo, la presencia de esa cantidad de chicos y chicas la necesito para vivir. Es decir, es parte de mi vida. Forma parte de mi vida real. (E1)

Yo, necesariamente, necesito dar clase (G2)

Yo enseño porque me gusta comunicar lo que me pasa, lo que me fascina y me deslumbra... (L1)

La clase para mí es un rompecabezas, un desafio que me gusta (G1)

Y, finalmente, aparece aquello que trasciende la docencia y la reinterpreta en claves que la ciencia tradicional no podría soportar, como el amor, el misterio, el deseo o la pasión, no como cuestiones paralelas - de una dimensión alternativa-, sino constitutivas y entretejidas en el entramado de la enseñanza:

[En respuesta a la consulta sobre sus preocupaciones docentes]... Tratar de que encuentren amor. Que se cuelguen de las cosas que están entre las cosas. Hacer un poema con algo que no se toca, que no se ve. (A1)

(...) uno debe tener deseo de que el otro entienda. Si uno sabe y parte de la idea de que el discurso es poder -lo pienso foucaultianamente- uno debe desear que el otro entre al orden del discurso, porque entrar al orden del discurso es poder tomar la palabra; es poder entender de qué se está hablando y eso es una forma de tomar el poder, el poder que implica saber, saber de qué se está hablando. Esto implica un claro posicionamiento. (...) Implica un esfuerzo, un esfuerzo didáctico enorme y eso implica una determinada voluntad. Hay que quererlo, hay que desearlo. (F1)
Yo creo que hay algo del cuerpo que enseña. Hay algo del cuerpo que cautiva la atención. Una especie de vigor, de pasión, de pathos en el sentido griego de la afección. No hay que escatimar el sentimiento humano de sentirse afectado por la clase. Yo creo que hay algo ahí, que opera como una forma de contagio, como un entusiasmo de mostrar el entusiasmo. Me parece que puede ser una herramienta que entusiasma, amén de convertirse en un elemento que mantiene la atención. Los cuerpos, las voces, las letras, los colores de las escrituras, todos constituyen una trama; una trama visual, una imagen puesta en movimiento que contribuye a las ideas. En las ideas hay algo muerto. (F1)

Vale la pena enseñar el placer. Cuanto más sabemos es cuánto más podemos sacar de un texto, cuando conocemos lo que rodea, o conocemos de la filosofía, o de la época, cada vez leemos más $(\mathrm{L} 1)$

Yo creo en el momento del aula; creo que cuando están todos atentos y están aprendiendo, ese es el momento mágico (L1)

\section{Conclusiones}

Proponíamos al principio, compartir los aprendizajes que la investigación narrativa ha posibilitado en el escenario de la formación del profesorado en el nivel superior. Argumentábamos, entonces, respecto de su potencia para la revuelta ontológica, epistemológica y política y compartíamos la intención de recorrer los avances tanto en términos de tesis conceptuales como en el lenguaje complejo y directo del relato del campo. Creemos que tal potencia ha quedado manifiesta y nos permite aventurar algunas nuevas conclusiones o instancias de síntesis, en el movimiento orgánico y espiralado que la mirada integrada del enfoque posibilita.

El cambio al que asistimos no comporta modificaciones en los componentes de una escena, sino que implica un necesario e inevitable, cambio radical de paisaje. En términos de Santos (2000), estamos entre la muerte y la utopía; en ese espacio extraordinariamente potente que libera las normas y habilita una creatividad sin precedentes. El valor de la investigación narrativa atestigua -y permite- este pasaje.

Si bien hay aún muchos reparos respecto del valor "técnico" del conocimiento singular, la idiosincrasia del caso único e irrepetible -con exponentes de inquietante sensatez, como Vasilachis de Giladino (2012) y su denuncia del reduccionismo a lo existencial, que puede hacernos perder de vista lo común frente a una identidad que necesariamente requiere ambos componentes, lo esencial y lo existencial- tales cuestionamientos son, tal vez, evidencia 
del "vértigo" que implica remover la base de una lógica de pensamiento eurocéntrica, y su fe en la posibilidad de conocer sin ambigüedades. Si existe lo esencial, si puede ser advertido, debe ser conocido como una construcción histórica contingente y factible de ser cambiada.

Como ha sido puesto en evidencia, la investigación narrativa se propone como campo de interés primario "(...) ese conocimiento social subjetivo e intersubjetivo y la construcción y cocreación activas de dicho conocimiento por parte de los agentes humanos, que es producido por [y productor de, nos animamos a agregar] la conciencia humana." (Guba \& Lincoln, 2012, p.55). La fertilidad de estos terrenos es inmensa, como esperamos haya quedado de manifiesto en las citas.

Cuando la validez tradicional se transforma en régimen de verdad, proponer la validez de la autenticidad (Guba \& Lincoln, 2012), la validez cristalina (Richardson, 1997) o la validez rizomática (Lather, 1993), entre otras muchas opciones, se presenta como un derecho político a recurrir a nuevas metáforas para nombrar lo que la tradición eurocentrista deja por fuera. Es una moción politica, porque rebate tanto la credibilidad en la simplicidad del mundo (que podría ser, según la ciencia moderna, "descubierto" o decodificado) como devela el ocultamiento de lógicas de poder muy eficaces en la sujeción simbólica. Es una moción epistémica porque cuestiona las posibilidades de construcción de conocimiento. Pero es, fundamentalmente, epistémico-politica porque reconoce la necesaria y potente imbricación entre ambas cuestiones.

Sin una revuelta epistémico-política hecha posible por la recuperación de la narrativa, la ciencia se quedaría fuera del universo aún enigmático de lo espiritual, el reino de lo estético, el dominio de lo corporal en su momento prediscursivo (Wacquant, 2008) y muchos otros "conocimientos" que solo se ausentan en el discurso científico tradicional, pero de ningún modo se retraen en la constitución de los mundos simbólicos que habitan las personas.

Quedan pendientes, como condición saludable de la investigación, una profundización aún más sustantiva de estos otros múltiples modos de conocer exiliados del discurso científico, pero fuertemente constitutivos y constituyentes, de las subjetividades docentes.

\section{Agradecimientos y reconocimientos}

Los hallazgos y tesis presentadas en este manuscrito tienen raigambre en las experiencias de investigación del Grupo de Investigaciones en Educación y Estudios Culturales (Gieec) ${ }^{7}$ de la Universidad de Mar del Plata. En los últimos doce años y en torno a seis proyectos bianuales acreditados, el grupo ha sacado a la luz un gran número de publicaciones nacionales e internacionales, desarrollado actividades académicas de posgrado y encuentros científicos y promovido redes de académicos y profesionales en Argentina, el resto de Latinoamérica y Europa, en torno a la formación del profesorado desde la perspectiva narrativa. A partir de los trabajos incipientes sobre buena enseñanza en los profesorados, hasta la definición de agendas pedagógico-políticas alternativas a los enfoques tradicionales de la formación docente, la producción del grupo es hoy referente en la región por sus desarrollos en el enfoque (auto)biográfico narrativo, la profundización en las indagaciones sobre la emoción, los afectos y las pasiones en la enseńanza y el giro hacia el pensamiento descolonial y la redefinición de condiciones para la didáctica del nivel superior.

\section{Referencias}

Angenot, M. (2012). El discurso social. Los límites históricos de lo pensable y lo decible. Buenos Aires: Siglo veintiuno.

Bruner, J. (1997). La educación, puerta de la cultura. Madrid: Visor.

Bruner, J. (2003) La fábrica de historias: derecho, literatura, vida. Buenos Aires: Fondo de Cultura Económica.

Cairo, H., \& Grosfoguel, R. (2010). Descolonizar la modernidad, descolonizar Europa: un diálogo Europa-América Latina. Madrid: IEPALA.

Castro-Gómez, S. (2005). La hybris del punto cero: ciencia, raza e Ilustración en la Nueva Granada (1750-1816). Bogotá: Editorial Pontificia Universidad Javeriana.

Denzin, N., \& Lincoln, Y. (2012). Paradigmas y perspectivas en disputa. Manual de investigación cualitativa. Barcelona: Gedisa.

Geertz, C. (1987). La interpretación de las culturas. México: Gedisa.

Grüner, E. (2010). La oscuridady las luces. Buenos Aires: Edhasa.

Guba, E., \& Lincoln, Y. (2012). Controversias paradigmáticas, contradicciones y convergencias emergentes. En N. Denzin \& Y. Lincoln (Eds.), Paradigmas y perspectivas en disputa. Manual de investigación cualitativa (pp.38-78. Vol. II). Barcelona: Gedisa.

7. El Gieec desarrolla su actividad en el CIMEd (Centro de Investigaciones Multidisciplinarias en Educación) de la Facultad de Humanidades, Universidad Nacional de Mar del Plata, Argentina. 
Guyot, V. (2007). Las prácticas del conocimiento. Un abordaje epistemológico. Educación. Investigación. Subjetividad. Argentina: Ediciones LAE.

Kincheloe, J., \& McLaren, P. (2012). Replanteo de la teoría crítica y de la investigación cualitativa. En N. Denzin \& Y. Lincoln (Eds.), Paradigmas y perspectivas en disputa. Manual de investigación cualitativa (pp. 241-315. Vol. II). Barcelona: Gedisa.

Lander, E. (2011). Ciencias sociales: saberes coloniales y eurocéntricos. En E. Lander (Comp.), La colonialidad del saber: eurocentrismo y ciencias sociales: perspectivas latinoamericanas (pp. 4-23). Buenos Aires: Ciccus Ediciones.

Lather, P. (1993). Fertile Obsession: Validity after Post-structuralism. Sociological Quarterly, 34, 673-693.

Litwin, E. (2005). El campo de la didáctica: en búsqueda de una nueva agenda. En A. Camilloni, M. Davini, G. Eldestein, E. Litwin. M. Souto \& S. Barco (Comp.), Corrientes Didácticas Contemporáneas (pp. 91-116). Buenos Aires: Paidós.

Mignolo, W. (1999). Colonialidad del poder y diferencia colonial. Lima: Anuario Mariateguiano.

Morín, E. (1999). Seven complex lessons in education for the future. Paris: UNESCO Publishing.

Porta, L., \& Yedaide, M. M. (2014). La investigación biográfico narrativa. Desafíos ontológicos para la investigación y la enseñanza en la formación de formadores. Sophia: colección de Filosofía de la Educación, 17(2), 177-193.

Richardson, L. (1997). Fields of Play: Constructing an Academic Life. NJ: Rutgers University Press.

Ryan, B. A. (1999). Does Postmodernism Mean the End of Science in the Behavioral Sciences, and Does It Matter Anyway?. Theory and Psychology, 9(4), 483-502.

Santos, B. S. (2000). Crítica de la razón indolente: contra el desperdicio de la experiencia. Para un nuevo sentido común: la ciencia, el derecho y la politica de la transición paradigmática. España: Descleé de Brouwer.

Santos, B. S. (2009). Epistemología del sur. México: Siglo XXI Editores.

Saukko, P. (2012). Metodologías para los estudios culturales. Un enfoque integrador. En N. Denzin \& Y. Lincoln (Eds.), Paradigmas y perspectivas en disputa. Manual de investigación cualitativa (pp. 316-340. Vol. II). Barcelona: Gedisa.

Vasilachis de Gialdino, I. (2012). De "la" forma de conocer a "las" formas de conocer. En N. Denzin \& Y. Lincoln (Eds.), Paradigmas y perspectivas en disputa. Manual de investigación cualitativa (pp. 11-26. Vol. II). Barcelona: Gedisa.

Wacquant, L. (2008). Conexiones carnales: sobre corporización, aprendizaje y pertenencia. Revista Pensar, 3(4), 12-41. 